\title{
Autoren- und Inhaltsübersicht
}

Dr. Christian Walter

Max-Planck-Institut für ausländisches öffentliches Recht und Völkerrecht

Heidelberg

$\S 1$ Geschichte und Entwicklung der Europäischen Grundrechte und Grundfreiheiten

Dr. Dirk Ehlers

Professor an der Universität Münster

$\S 2$ Allgemeine Lehren . . . . . . . . . . . . . . . . . 21

Dr. Robert Uerpmann

Professor an der Universität Regensburg

$\S 3$ Höchstpersönliche Rechte und Diskriminierungsverbot f . . . . . . 47

Dr. Thilo Marauhn

Professor an der Universität Gießen

$\S 4$ Kommunikationsgrundrechte

Dr. Bernhard W. Wegener

Professor an der Universität Münster

$\S 5$ Wirtschaftsgrundrechte

Dr. Dr. Christoph Grabenwarter

Professor an der Universität Bonn

$\S 6$ Justiz- und Verfahrensgrundrechte $\ldots \ldots \ldots \ldots \ldots$

Dr. Dirk Ehlers

Professor an der Universität Münster

$\S 7$ Allgemeine Lehren . . . . . . . . . . . . . . . . . . 147

Dr. Astrid Epiney

Professorin an der Universität Freiburg Schweiz

$\S 8$ Freiheit des Warenverkehrs

Dr. Ulrich Becker

Professor an der Universität Regensburg

$\S 9$ Arbeitnehmerfreizügigkeit

Dr. Christian Tietje

Professor an der Universität Halle

$\S 10$ Niederlassungsfreiheit

Dr. Eckhard Pache

Professor an der Universität Würzburg

$\S 11$ Dienstleistungsfreiheit 
Dr. Peter v. Wilmowsky

Professor an der Universität Erfurt

$\S 12$ Freiheit des Kapital- und Zahlungsverkehrs

Dr. Dirk Ehlers

Professor an der Universität Münster

$\S 13$ Allgemeine Lehren

Dr. Frank Schorkopf

Max-Planck-Institut für ausländisches öffentliches Recht und Völkerrecht

Heidelberg, $\mathrm{zZ}$ wiss Mitarb am Bundesverfassungsgericht

$\S 14$ Persönlichkeits- und Kommunikationsgrundrechte . . . . . . . . . . . . 339

Dr. Matthias Ruffert

Professor an der Universität Jena

$\S 15$ Grundrecht der Berufsfreiheit

Dr. Christian Calliess

Professor an der Universität Graz

$\S 16$ Eigentumsgrundrecht

Dr. Thorsten Kingreen

Professor an der Universität Bielefeld

$\S 17$ Gleichheitsrechte

Dr. Jörg Gundel

Priv.-Doz. an der Freien Universität Berlin

$\S 18$ Verfahrensgrundrechte

Dr. Christian Calliess

Professor an der Universität Graz

$\S 19$ Die Europäische Grundrechts-Charta . . . . . . . . . . . . . . . . . .

Dr. Stefan Kadelbach

Professor an der Universität Münster

$\S 20$ Die Unionsbürgerrechte 